Article

\title{
Trends in the Airglow Temperatures in the MLT Region-Part 1: Model Simulations
}

\author{
Tai-Yin Huang $1, * \mathbb{D}$ and Michael Vanyo ${ }^{2}$ \\ 1 Department of Physics, The Pennsylvania State University, Lehigh Valley Campus, Center Valley, \\ PA 18034, USA \\ 2 Department of Physics, The Pennsylvania State University, University Park, State College, PA 16801, USA; \\ mmv5@psu.edu \\ * Correspondence: tuh4@psu.edu
}

Received: 16 April 2020; Accepted: 5 May 2020; Published: 6 May 2020

\begin{abstract}
Airglow intensity-weighted temperature variations induced by the $\mathrm{CO}_{2}$ increase, solar cycle variation (F10.7 as a proxy) and geomagnetic activity (Ap index as a proxy) in the Mesosphere and Lower Thermosphere (MLT) region were simulated to quantitatively assess their influences on airglow temperatures. Two airglow models, MACD-00 and OHCD-00, were used to simulate the $\mathrm{O}\left({ }^{1} \mathrm{~S}\right)$ greenline, $\mathrm{O}_{2}(0,1)$ atmospheric band, and $\mathrm{OH}(8,3)$ airglow temperature variations induced by these influences to deduce the trends. Our results show that all three airglow temperatures display a linear trend of $\sim-0.5 \mathrm{~K} /$ decade, in response to the increase of $\mathrm{CO}_{2}$ gas concentration. The airglow temperatures were found to be highly correlated with Ap index, and moderately correlated with F10.7, with the $\mathrm{OH}$ temperature showing an anti-correlation. The F10.7 and Ap index trends were found to be $\sim-0.7 \pm 0.28 \mathrm{~K} / 100 \mathrm{SFU}$ and $\sim-0.1 \pm 0.02 \mathrm{~K} / \mathrm{nT}$ in the $\mathrm{OH}$ temperature, $4.1 \pm 0.7 \mathrm{~K} / 100 \mathrm{SFU}$ and $\sim 0.6 \pm 0.03 \mathrm{~K} / \mathrm{nT}$ in the $\mathrm{O}_{2}$ temperature and $\sim 2.0 \pm 0.6 \mathrm{~K} / 100 \mathrm{SFU}$ and $\sim 0.4 \pm 0.03 \mathrm{~K} / \mathrm{nT}$ in the $\mathrm{O} 1 \mathrm{~S}$ temperature. These results indicate that geomagnetic activity can have a rather significant effect on the temperatures that had not been looked at previously.
\end{abstract}

Keywords: airglow temperature; solar cycle variation; $\mathrm{CO}_{2}$; geomagnetic activity

\section{Introduction}

Global warming has been recognized as being responsible for extreme weather events in recent years. The cause of global warming has been attributed to be of anthropogenic origin. The pioneering work by [1], who did a numerical study to investigate the impact on the atmospheric structure caused by the $\mathrm{CO}_{2}$ and $\mathrm{CH}_{4}$ concentration change in the lower atmosphere, has revealed that gas concentration and temperature would change in response to the change of anthropogenic gas emissions. In particular, the study predicted a $10 \mathrm{~K}(50 \mathrm{~K})$ cooling in the mesosphere (thermosphere) and a 30-50\% decrease in the number densities of major gas species and atomic oxygen at $300 \mathrm{~km}$, for a doubling of $\mathrm{CO}_{2}$ and $\mathrm{CH}_{4}$ gas concentrations.

Several studies have attempted to identify global warming footprint from various sources. For example, satellite drag measurements have been used to find if there exists any decreasing trend in neutral density [2-5]. See [6] for a comprehensive comparison of these studies. One big challenge for the trend analysis was that solar cycle variation would cause neutral density variation as well. Needless to say, in order to quantify global warming of anthropogenic origin, we need to separate the effects by natural variabilities from those by anthropogenic gas emissions.

As shown in [7], airglow is very sensitive to global change, which is not surprising, because airglow is known to be sensitive to atmospheric conditions. However, as pointed it out by [8], "using airglow measurements to deduce the change by the increase of anthropogenic gas emissions presents some 
challenges ..." The challenges come from the fact that there are variations in the measurements by other influences (be it dynamical or natural variability) that need to be distinguished from the variation caused by the increase of anthropogenic gas emissions. The study by [7] also concluded that solar variability and dynamics are two main factors that affect the airglow variations in the measurements. Therefore, the current work does not include the dynamics intentionally.

That we need to quantitatively assess the variations of airglow intensities and temperatures by the known influences was the motivation for the current study and previous numerical studies by [8-10]. As pointed out in [8], the advantage of a numerical approach is that we can do controlled simulations to better assess the individual impact of the influences. The author of [9] did a simulation study to investigate how airglow intensities and Volume Emission Rates (VERs) would change in response to hypothetical scenarios of $\mathrm{CO}_{2}$ doubling, $\mathrm{CO}_{2}$ decreased by half and $\mathrm{CO}_{2}$ increased by $10 \%$. The work by [8] simulated the time series of airglow intensities, VERs, and airglow peak heights due to the influences of $\mathrm{CO}_{2}$ concentration increase, using realistic $\mathrm{CO}_{2}$ measurements and solar cycle variation for over a solar cycle time period. The recent study by [10] simulated the time series of the aforementioned airglow quantities due to $\mathrm{CO}_{2}$ increase, solar cycle variation and geomagnetic activity over a much longer time period of 55 years.

In the current study, we use OHCD-00 and MACD-00 models, which employ the NRLMSISE-00 model [11] as a reference model [12] for the simulations of airglow temperatures. This work is a follow-up of [10], focusing on airglow temperatures but with two major differences-the current work uses the NRLMSISE-00 model, whereas [10] used MSISE-90 in their OHCD-90 and MACD-90 models, and the current work expands the years of interest from 1960 to 2019. The airglow intensity-weighted temperatures are obtained from the NRLMSISE-00 kinetic temperatures, weighted by the airglow VERs in the airglow models. The variations induced by the influences $\left(\mathrm{CO}_{2}\right.$ gas concentration increase, F10.7, and Ap index variation) are simulated with OHCD-00 and MACD-00 models, and then the trends in the airglow temperatures by these influences are deduced.

The current work is focused on the model simulations of airglow temperatures under the influences of $\mathrm{CO}_{2}$ increase, F10.7 and Ap index variations. We will defer the comparisons to observation to a follow-up paper ("Trends in the Airglow Temperatures in the MLT Region - Part 2: Observations"), in which we will compare our model simulations and the reanalysis of some other observations to the Sounding of the Atmosphere using Broadband Emission Radiometer (SABER) observations.

The paper is organized as follows. The models and data sources $\left(\mathrm{CO}_{2}, \mathrm{~F} 10.7\right.$, and Ap index $)$ are described in Section 2. Results are presented in Section 3. Discussion is in Section 4 and Conclusions are in Section 5.

\section{Models and Data Sources}

In this study, airglow intensity-weighted temperatures of $\mathrm{OH}(8,3), \mathrm{O}_{2}(0,1)$ atmospheric band, and $\mathrm{O}\left({ }^{1} \mathrm{~S}\right)$ greenline emissions were simulated for a location at latitude $18 \mathrm{~N}$ and longitude $290 \mathrm{E}$, the same as in [10]. Two airglow models, OHCD-00 and MACD-00 models, were used with the values of $\mathrm{CO}_{2}$ concentration level, F10.7 and Ap index input to the models for a time period from year 1960 to year 2019.

The $\mathrm{OH}$ Chemistry Dynamics (OHCD) model considers essential chemical reactions for $\mathrm{OH}$ airglow [13,14], whereas the Multiple-Airglow Chemistry Dynamics (MACD) model considers chemical reactions for $\mathrm{O}_{2}$ atmospheric bands and $\mathrm{O}\left({ }^{1} \mathrm{~S}\right)$ greenline [15,16]. The extension of the airglow models indicates which reference model is used. For example, the OHCD-90 and MACD-90 models use the MSISE-90 model [17] as a reference model, and they were used in [10] to simulate airglow intensities and VERs. Detailed information about the different versions of the OHCD and MACD models and the references therein can be found in [12]. Suffice to say that the OHCD-00 and MACD-00 models use NRLMSISE-00 as the reference model to obtain the vertical profiles of major gas species' number density, atomic oxygen, atomic hydrogen and atmospheric temperature. Vertical profiles of minor gas 
species' number densities of $\mathrm{O}_{3}, \mathrm{OH}(\mathrm{v}=0), \mathrm{OH}(\mathrm{v}=8), \mathrm{HO}_{2}, \mathrm{O}_{2}\left({ }^{1} \mathrm{C}\right), \mathrm{O}_{2}(0,1)$ and $\mathrm{O}\left({ }^{1} \mathrm{~S}\right)$ are obtained from the OHCD-00 and MACD-00 models, based on the chemical equilibrium requirement.

Three scenarios have been simulated. The first scenario, S1, simulates the time series of airglow temperatures under the influence of F10.7 and Ap index variations, when the $\mathrm{CO}_{2}$ gas concentration level is kept fixed at its value in year 1960. The second scenario, S2, simulates the time series of airglow temperatures under the influence of the $\mathrm{CO}_{2}$ gas concentration increase, when F10.7 and Ap index values are kept fixed at their values in year 1960. The third scenario, S3, simulates the time series of airglow temperatures under the influence of F10.7, Ap index and $\mathrm{CO}_{2}$ changes.

The $\mathrm{CO}_{2}$ gas concentration (in ppm) was obtained from the NOAA's website and the F10.7 index values (in Solar Flux Unit, SFU) were taken from NASA's website. The F10.7 index was used as a proxy for the 11-year solar cycle variation. The Ap index (in nT) values were obtained from the World Data Center for Geomagnetism, Kyoto website. These data from 1960 to 2019 were further averaged to produce the annual means.

The solar cycle and geomagnetic activity variations of the atmospheric species' number densities and temperature are from the F10.7 and the Ap index dependence of these quantities output from the NRLMSISE-00 model. Note that the F10.7 and Ap variations have not been carried below 110 and $90 \mathrm{~km}$, respectively, where their coefficient became insignificant in the MSISE-90 or NRLMSISE-00 models. We should also point it out that the MSISE-90 and NRLMSISE-00 are empirical models, meaning that the incorporated observations inherently contained the signatures of solar cycle variation and geomagnetic activity. So even when the F10.7 is not explicitly "turned on" below $110 \mathrm{~km}$ in the model, the solar cycle influence is in the data implicitly. Also, the advantage of using NRLMSISE-00 over MSISE-90 is that it contains more and recent data with more coverage in locations and data sampling. The change of the atmospheric gas concentrations and temperature due to the increase of the $\mathrm{CO}_{2}$ gas concentration were found by using the analytic expressions listed in Table 1 of [8], following the procedure described in [8].

\section{Results}

Figure 1 shows the $\mathrm{OH}(8,3)$ airglow intensity-weighted temperature (OH temperature hereafter) as a function of year for the three scenarios. Figure 1a shows the temperatures (axis on left) and F10.7 values (axis on right), and Figure $1 \mathrm{~b}$ shows the temperatures (axis on left) and Ap index (axis on right). Our simulation results of S1 (red line with dots) show a strong anti-correlation between the $\mathrm{OH}$ temperature and Ap index. The correlation between the $\mathrm{OH}$ temperature and F10.7 is not as obvious. In some years, it showed a strong positive correlation during the solar maximum in solar cycle 20 (1968-1970), solar cycle 21 (1978-1982) and solar cycle 23 (1999-2002), and in some years, especially during the solar minima, it showed an anti-correlation. The temperature varies between 193.9 and 197.9 K, a 4.0-K variation over the 60 years. The S2 scenario (blue line with upright triangles) shows that the $\mathrm{OH}$ temperature decreases linearly with the increase of $\mathrm{CO}_{2}$ concentration. The temperature change is about $3.2 \mathrm{~K}$ in the 60 years, indicating a $-0.53 \mathrm{~K} /$ decade trend. For the $\mathrm{S} 3$ scenario (green line with squares), the temperature varies between 192.2 and $196.8 \mathrm{~K}$, a 4.6-K variation. In looking at the S1 and $\mathrm{S} 3$ results, we can see that they share the same features, but the $\mathrm{S} 3$ results are shifted downward due to the $\mathrm{CO}_{2}$ increase, and the separation between $\mathrm{S} 1$ and $\mathrm{S} 3$ temperatures gets larger in time, when the influence of $\mathrm{CO}_{2}$ increase gets larger.

The $\mathrm{O}_{2}(0,1)$ airglow intensity-weighted temperature $\left(\mathrm{O}_{2}\right.$ temperature) for the three scenarios is shown in Figure 2. Figure 2a shows a moderate correlation of the $\mathrm{O}_{2}$ temperature with F10.7. In general, the $\mathrm{O}_{2}$ temperature follows the overall F10.7 variation, and a close correlation is observed during the solar maximum in solar cycles 20 (1967-1970), 22 (1988-1991) and 23 (2000-2002). Figure $2 b$ shows that the $\mathrm{O}_{2}$ temperature is highly correlated with Ap index. The temperature varies between 193.4 and $204.4 \mathrm{~K}$, showing a $11-\mathrm{K}$ variation for $\mathrm{S} 1$. The $\mathrm{O}_{2}$ temperature also shows a decreasing trend, $-0.55 \mathrm{~K} /$ decade, in response to the increase of $\mathrm{CO}_{2}$ concentration for $\mathrm{S} 2$. For the $\mathrm{S} 3$ scenario, the temperature varies from 191.1 to $203.8 \mathrm{~K}$, showing a $12.7-\mathrm{K}$ variation. The presence of $\mathrm{CO}_{2}$ increase amplifies the $\mathrm{O}_{2}$ temperature variation with time. 

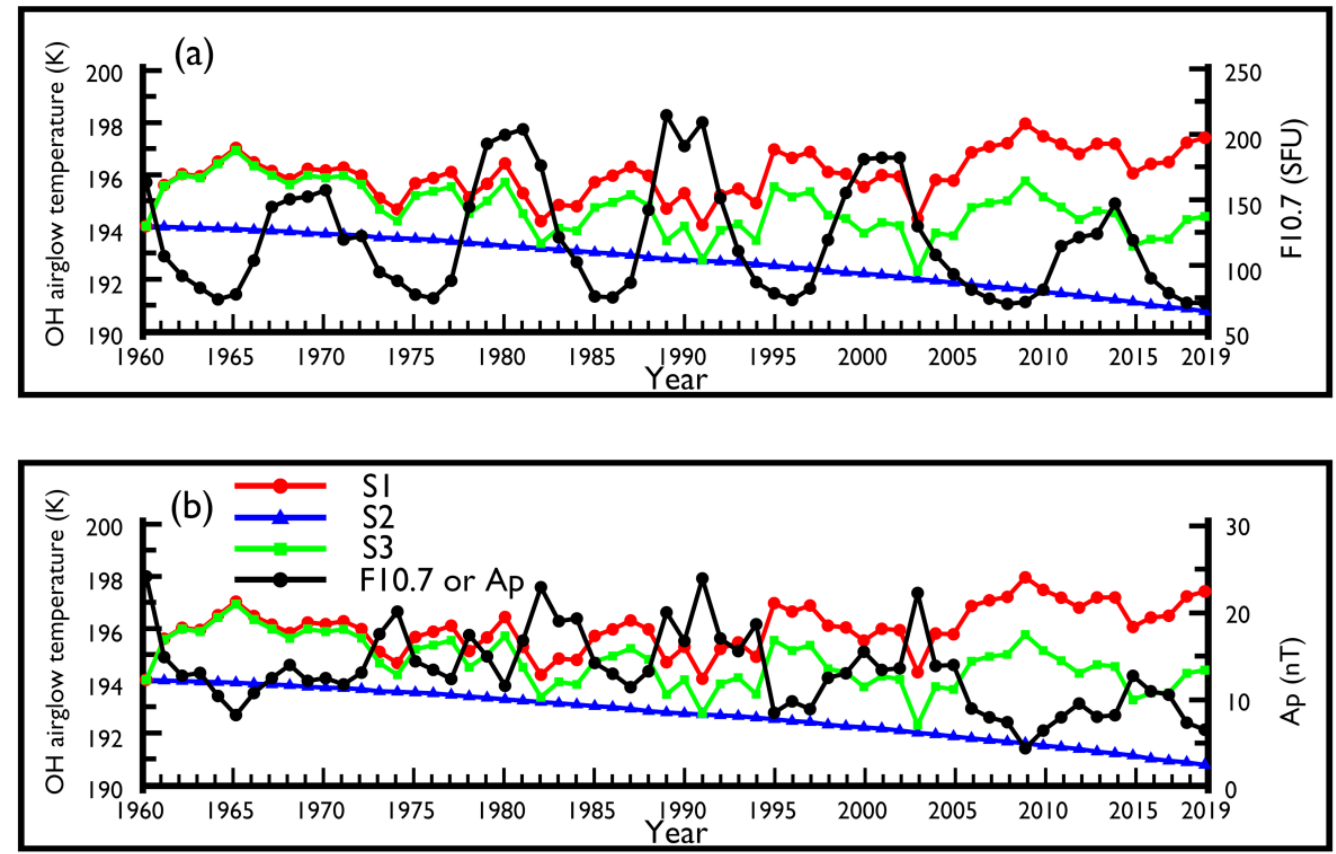

Figure 1. (a) Time series of the simulated $\mathrm{OH}$ temperature (axis on left) and F10.7 (axis on right) in the top panel for the three scenarios. (b) The same plot but with Ap index (axis on right) is on the bottom panel. The red line with dots denotes the first scenario S1. The blue line with upright triangles denotes the second scenario S2. The green line with squares denotes the third scenario S3. The solid line with diamonds denotes either F10.7 or Ap index.

Figure 3 shows a similar plot for $\mathrm{O}\left({ }^{1} \mathrm{~S}\right)$ airglow intensity-weighted temperature (O1S temperature). The O1S temperature displays a similar response to the influences of F10.7, Ap index, and $\mathrm{CO}_{2}$ increase as the $\mathrm{O}_{2}$ temperature for the three scenarios. The O1S temperature overall follows the F10.7 variation, with an exception that occurred during the solar maximum in solar cycle 21 (1979-1981). This is also seen in the $\mathrm{O}_{2}$ temperature. The $\mathrm{O} 1 \mathrm{~S}$ temperature also shows a high correlation with Ap index. The O1S temperature in $\mathrm{S} 1$ changes within a $6.9-\mathrm{K}$ range. The increase of $\mathrm{CO}_{2}$ concentration leads to a decreasing temperature with a trend of $-0.52 \mathrm{~K} /$ decade. For the $\mathrm{S} 3$ scenario, our results show that the temperature fluctuates in a 9.0-K range. The results shown in Figures 1-3 indicate that the airglow temperatures will decrease in response to the increase of $\mathrm{CO}_{2}$ gas concentration with a magnitude of $\sim 0.5 \mathrm{~K} /$ decade. Our results also indicate that the $\mathrm{O}_{2}$ temperature shows a larger response to the F10.7 and Ap index variations than the O1S temperature and both temperatures show a positive correlation with F10.7 and Ap index. The $\mathrm{OH}$ temperature has the smallest response and is found to be anticorrelated with F10.7 and Ap index. In addition, the increase of $\mathrm{CO}_{2}$ gas concentration tends to amplify airglow temperature variation.

To see how well the airglow temperatures are correlated with either F10.7 or Ap index, we did a linear regression fit of the airglow temperatures as a function of F10.7 and as a function of Ap index using Equations (1) and (2), respectively.

$$
\begin{gathered}
T(F 10.7)=A+B * F 10.7 \\
T(A p)=A+B * A p
\end{gathered}
$$


O2(0,I) Airglow Intensity-weighted Temperature
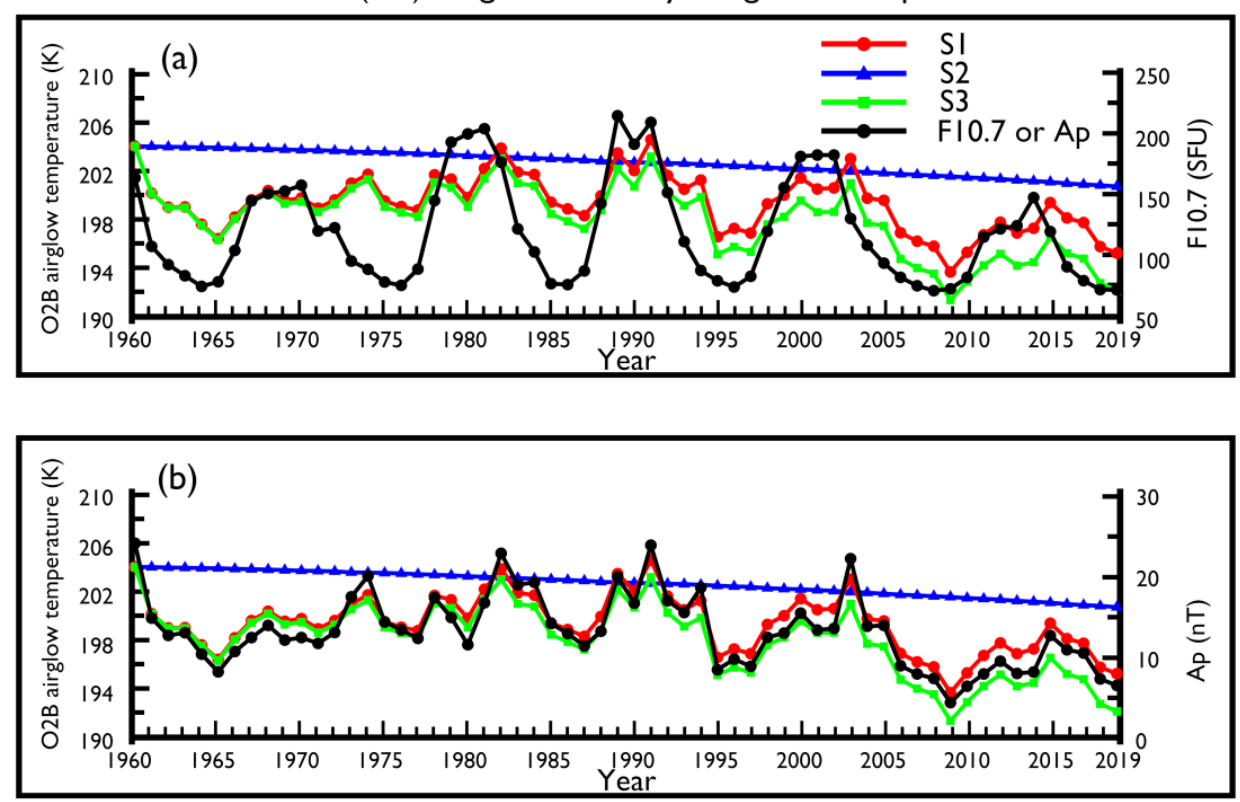

Figure 2. (a) Time series of the simulated $\mathrm{O}_{2}$ temperature (axis on left) and F10.7 (axis on right) in the top panel for the three scenarios. (b) The same plot but with Ap index (axis on right) is on the bottom panel.

Figure 4 shows the simulated airglow temperatures as a function of Ap index, along with the fits for S1. They all display a very high correlation with the Ap index, with the correlation coefficients $\sim 0.97$ and the fitting lines fit the data very well. The $\mathrm{OH}$ temperature shows an anticorrelation, whereas the $\mathrm{O}_{2}$ and $\mathrm{O} 1 \mathrm{~S}$ temperatures show a positive correlation with Ap index. The study by [10] reveals that major gas species' number density and kinetic temperature ratios are anticorrelated with the Ap index in the $\mathrm{OH}$ airglow region, e.g., Figure 2 of [10]. In the $\mathrm{O}_{2}$ and $\mathrm{O} 1 \mathrm{~S}$ airglow region, the major gas species' number density ratios remain anticorrelated with the Ap index, but the temperature ratio is found to be positively correlated with the Ap index. Our airglow temperatures, which are NRLMSISE-00 kinetic temperature weighted by the airglow VERs, show that the Ap index trends are similar to the trends in kinetic temperature, in that the sign of the trend is altitude-dependent. The simulated airglow temperatures, however, do not show such high correlation with F10.7, as shown in Figure 5. The data are scattered along the fitting lines. That being said, the airglow temperatures do show a moderate correlation with F10.7, as indicated by the correlation coefficients varying between 0.49 and 0.69. The $\mathrm{OH}$ temperature decreases with increasing F10.7, whereas the $\mathrm{O}_{2}$ and $\mathrm{O} 1 \mathrm{~S}$ temperatures increase with increasing F10.7.

The results of the linear regression analysis for each of the airglow temperatures for the three scenarios are listed in Table 1. For S1 and S3, the airglow temperatures were fitted as a function of F10.7 and as a function of the Ap index. For S2, the temperatures were fitted as a function of $\mathrm{CO}_{2}$ gas concentration. The correlation coefficient, $\mathrm{R}$, is also listed to show the goodness of the fit for each fitting. Based on the correlation coefficients, our results show that the airglow temperatures are well correlated with the Ap index, and moderately correlated with F10.7 for S1. The presence of $\mathrm{CO}_{2}$ in $\mathrm{S} 3$ decreases the fidelity of the fits with F10.7 or the Ap index. The O1S and $\mathrm{O}_{2}$ temperatures for $\mathrm{S} 3$ still show a very high correlation coefficient for the Ap index trend, but the $\mathrm{OH}$ temperature is affected the most, with the $\mathrm{R}$ value changing from $\sim 0.996$ for $\mathrm{S} 1$ to $\sim 0.545$ for S3. This implies that it is difficult to identify an Ap index trend in the $\mathrm{OH}$ temperature if the $\mathrm{CO}_{2}$ trend has not been removed first. As for the $\mathrm{O}_{2}$ and $\mathrm{O} 1 \mathrm{~S}$ temperatures, the Ap index trends are found to be a little bit larger when the $\mathrm{CO}_{2}$ gas concentration increases. For $\mathrm{S} 2$, the airglow temperatures all show a $\mathrm{CO}_{2}$ trend with a slope of $\sim-0.03$, with the $\mathrm{O}_{2}$ temperature having a slightly larger slope $(-0.035)$. Using the trend equations for 
S2, it should be fairly easy to infer the airglow temperature change in response to the change of $\mathrm{CO}_{2}$ gas concentration.

OIS Airglow Intensity-weighted Temperature
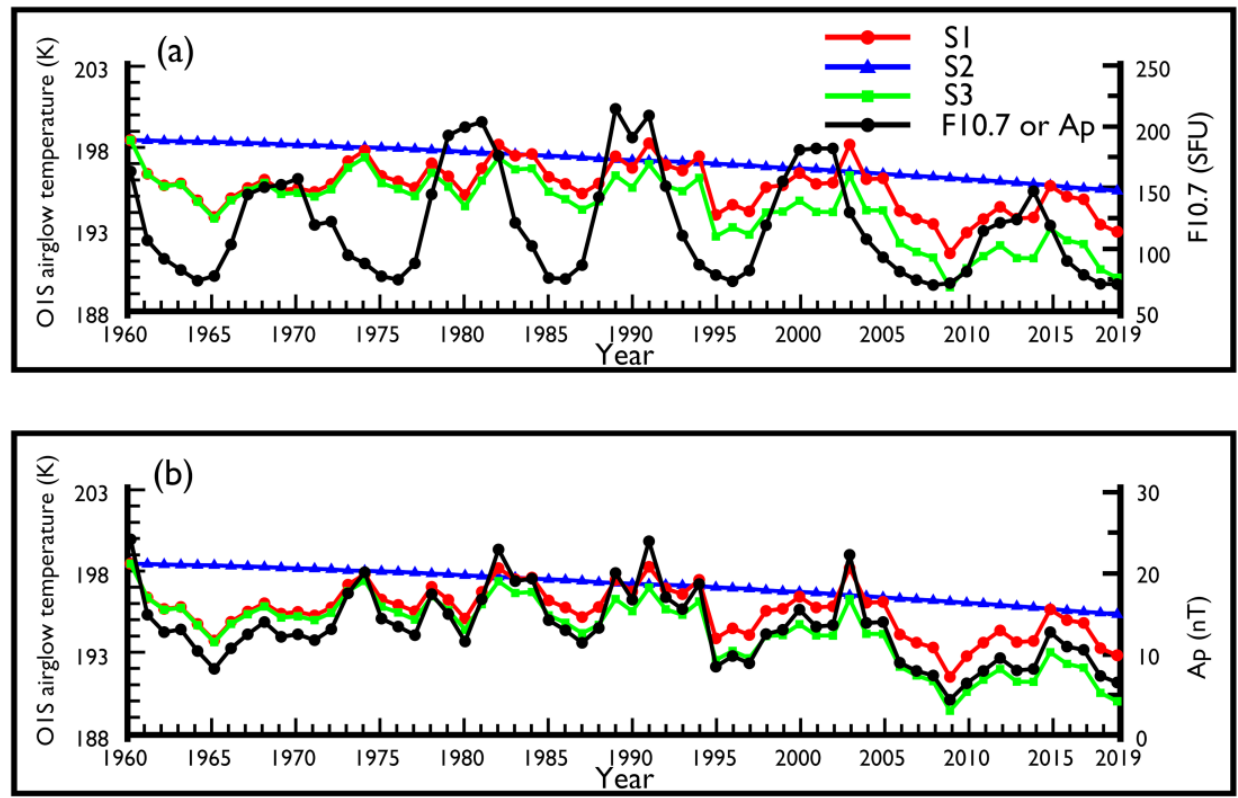

Figure 3. (a) Time series of the simulated O1S temperature (axis on left) and F10.7 (axis on right) in the top panel for the three scenarios. (b) The same plot but with Ap index (axis on right) is on the bottom panel.
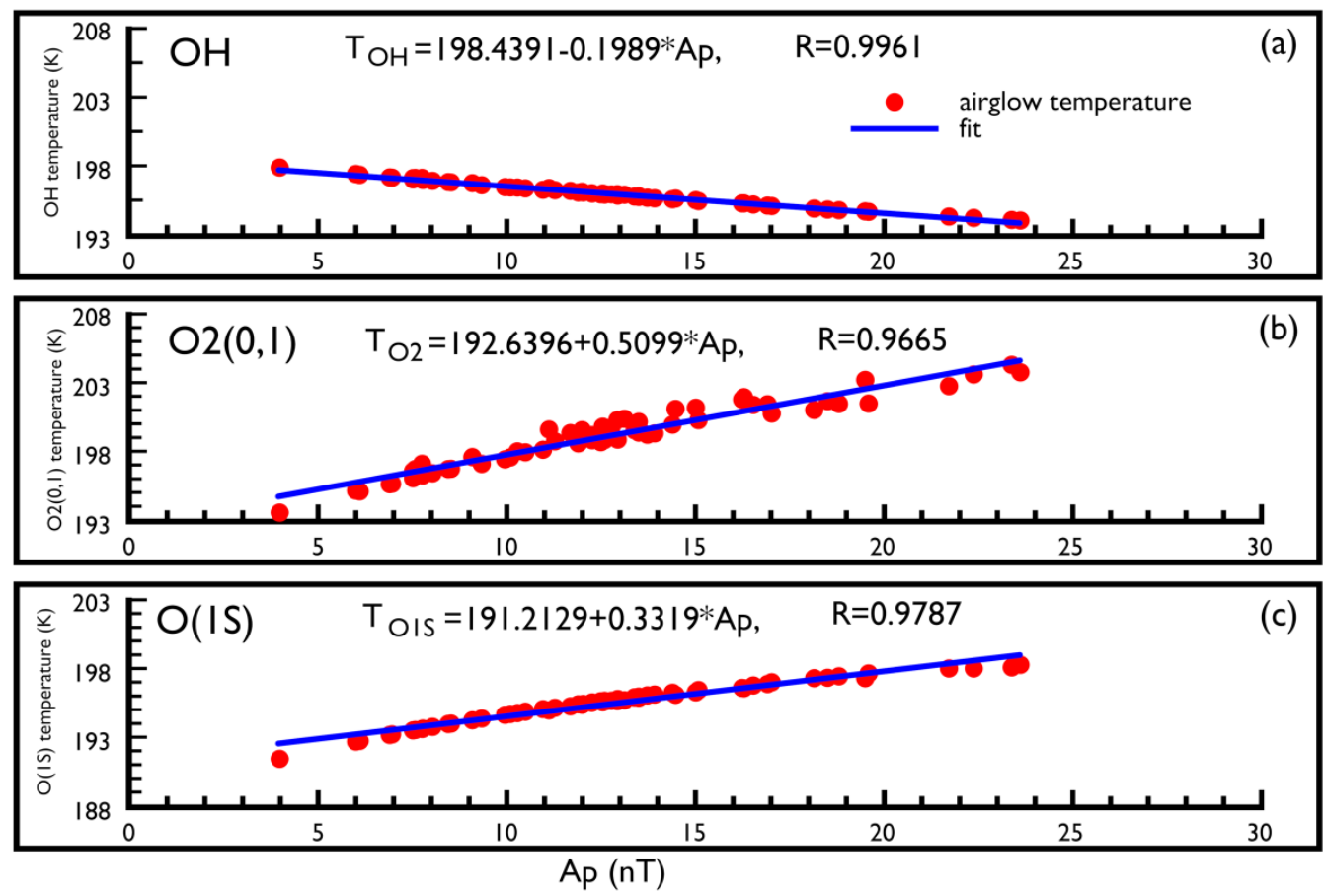

Figure 4. Linear regression of the simulated airglow temperature as a function of Ap index for $\mathrm{S} 1$ scenario. (a) For $\mathrm{OH}$, (b) for $\mathrm{O}_{2}$ and (c) for $\mathrm{O} 1 \mathrm{~S}$ temperature. The simulated airglow temperatures all display a very high correlation with the Ap index. 

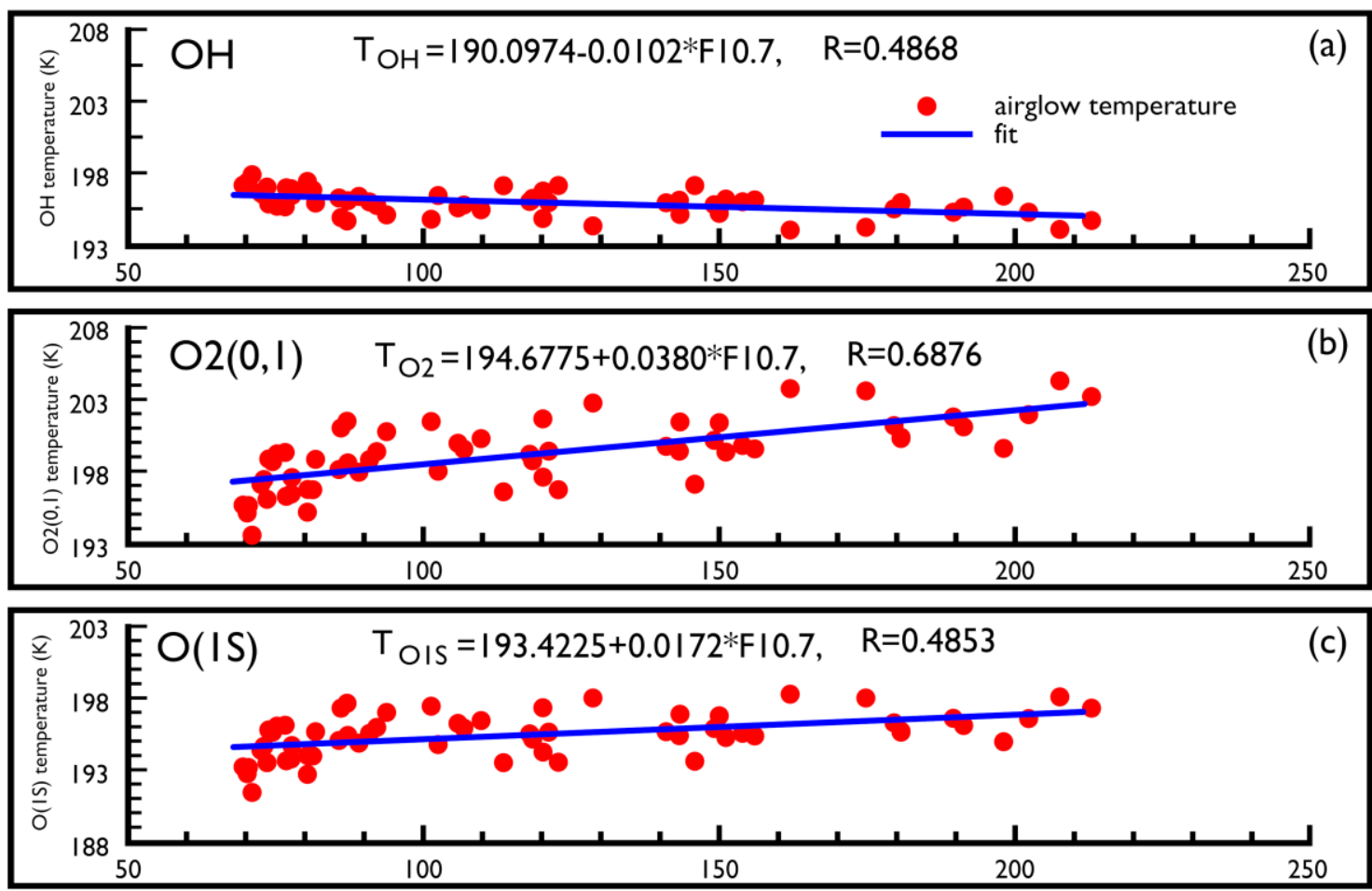

FI0.7 (SFU)

Figure 5. Linear regression of the simulated airglow temperature as a function of F10.7 index for $\mathrm{S} 1$ scenario. (a) For $\mathrm{OH}$, (b) for $\mathrm{O}_{2}$ and (c) for $\mathrm{O} 1 \mathrm{~S}$ temperature. The simulated airglow temperatures all display a moderate correlation with F10.7.

Table 1. Trends as a function of F10.7, Ap index, or $\mathrm{CO}_{2}$ gas concentration in $\mathrm{OH}(8,3)$ airglow, $\mathrm{O}_{2}(0,1)$ atmospheric band and $\mathrm{O}\left({ }^{1} \mathrm{~S}\right)$ greenline temperatures for the three Scenarios.

\begin{tabular}{|c|c|c|c|}
\hline Airglow Temperature (K) & Scenario & Trend Equation & $\mathbf{R}$ \\
\hline \multirow{5}{*}{$\mathrm{T}_{\mathrm{OH}(8,3)}$} & \multirow{2}{*}{ S1 } & $T_{\mathrm{OH}}=(-0.0102 \pm 0.0024) * F 10.7+197.1$ & 0.4868 \\
\hline & & $T_{\mathrm{OH}}=(-0.1989 \pm 0.0023) * \mathrm{Ap}+198.44$ & 0.9961 \\
\hline & S2 & $T_{\mathrm{OH}}=(-0.0345 \pm 0.00002) * \mathrm{CO}_{2}+204.88$ & 1.0 \\
\hline & \multirow{2}{*}{ S3 } & $T_{\mathrm{OH}}=(-0.0069 \pm 0.0028) * F 10.7+195.43$ & 0.3088 \\
\hline & & $T_{\mathrm{OH}}=(-0.1168 \pm 0.0236) * \mathrm{Ap}+196.1$ & 0.5448 \\
\hline \multirow{5}{*}{$\mathrm{T}_{\mathrm{O} 2(0,1)}$} & \multirow{2}{*}{ S1 } & $T_{O 2}=(0.0380 \pm 0.0053) * F 10.7+194.68$ & 0.6876 \\
\hline & & $T_{O 2}=(0.5099 \pm 0.0177) * \mathrm{Ap}+192.64$ & 0.9665 \\
\hline & S2 & $T_{\mathrm{O} 2}=(-0.0351 \pm 0.00002) * \mathrm{CO}_{2}+214.95$ & 1.0 \\
\hline & \multirow{2}{*}{ S3 } & $T_{\mathrm{O} 2}=(0.041 \pm 0.0070) * F 10.7+193$ & 0.6075 \\
\hline & & $T_{O 2}=(0.5960 \pm 0.0321) * A p+190.21$ & 0.9253 \\
\hline \multirow{5}{*}{$\mathrm{T}_{\mathrm{O}(1 \mathrm{~S})}$} & \multirow{2}{*}{ S1 } & $T_{O 1 S}=(0.0172 \pm 0.0041) * F 10.7+193.42$ & 0.4853 \\
\hline & & $T_{O 1 S}=(0.3319 \pm 0.0091) * A p+191.21$ & 0.9787 \\
\hline & S2 & $T_{O 1 S}=(-0.0330 \pm 0.00002) * \mathrm{CO}_{2}+208.79$ & 1.0 \\
\hline & \multirow{2}{*}{ S3 } & $T_{O 1 S}=(0.020 \pm 0.0057) * F 10.7+191.88$ & 0.4172 \\
\hline & & $T_{O 1 S}=(0.4084 \pm 0.0275) * A p+189.02$ & 0.8899 \\
\hline
\end{tabular}

\section{Discussion}

Several studies have performed a trend analysis on temperature measurements to determine if there existed a linear trend in the temperatures and/or any solar cycle dependence of the temperatures. For instance, [18] found a trend of $-0.89 \pm 0.55 \mathrm{~K} /$ decade and of $4.2 \pm 0.9 \mathrm{~K} / 100 \mathrm{SFU}$ in the $\mathrm{OH}$ airglow temperature from 1988 to 2015 , but noted that the multiple linear regression analysis that 
included linear and solar cycle terms was not enough to capture the observed long-term dynamics, and that there seemed to be a trend break in the data. The work by [19] found a cooling trend of $2.2 \pm 0.9 \mathrm{~K} /$ decade in the $\mathrm{OH}$ airglow temperature from 2000-2012. The $\mathrm{OH}$ temperature in Svalbard from 1983 to 2013 showed a temperature response of $3.6 \pm 4 \mathrm{~K} / 100 \mathrm{SFU}$ to solar influence, and a linear trend of $-0.2 \mathrm{~K} \pm 0.5 \mathrm{~K} /$ decade [20]. A cooling trend of $4 \pm 2 \mathrm{~K} /$ decade at $90 \mathrm{~km}$ in the meteor radar temperature observations from 2001-2012 [21]. The OH temperature at South Pole from 1994 to 2004 showed a temperature response of $4 \pm 1 \mathrm{~K} / 100 \mathrm{SFU}$, and a statistically insignificant linear trend of $\sim 1 \pm 2 \mathrm{~K} /$ decade [22]. Most of the linear trends in these studies were found to show a cooling trend, but a large variation with values ranging from $0.2 \mathrm{~K}$ to $4 \mathrm{~K}$ exist among these studies. These studies all found an F10.7 trend with a magnitude of $\sim 4 \mathrm{~K} / 100 \mathrm{SFU}$. The trends from these studies are listed in Table 2. We also note that none of these studies examined the temperature response to geomagnetic activity, so no information is provided.

Table 2. A list of F10.7 trends and linear trends from previous studies.

\begin{tabular}{cccc}
\hline & F10.7 Trend (K/100SFU) & Linear Trend (K/Decade) & Notes \\
\hline Kalicinsky et al. (2016) [18] & $4.2 \pm 0.9$ & $-0.89 \pm 0.55$ & OH temperature \\
\hline Perminov et al. (2014) [19] & - & $-2.2 \pm 0.9$ & OH temperature \\
\hline Holmen et al. (2014) [20] & $3.6 \pm 4$ & $-0.2 \pm 0.5$ & OH temperature \\
\hline Hall et al. (2012) [21] & - & $-4 \pm 2$ & Meteor radar temperature \\
\hline Azeem et al. (2007) [22] & $4 \pm 1$ & $\sim 1 \pm 2 *$ & OH temperature *
\end{tabular}

Our simulated airglow temperatures show a linear trend of $\sim-0.5 \mathrm{~K} /$ decade, which is due to the increase of $\mathrm{CO}_{2}$ gas concentration (see S2 in Table 1). Our cooling trend in the airglow temperatures is smaller than the trends found by $[19,21]$, but is close to the values obtained by $[18,20]$. Although our cooling trends might be different from some of the studies, it should be noted that our linear trends from the simulation results are due to the increase of $\mathrm{CO}_{2}$ gas concentration alone. In reality, temperature measurements might contain more information than what has been identified in the data. Our simulated airglow temperatures for S3 shows a trend of $-0.69 \pm 0.28 \mathrm{~K} / 100 \mathrm{SFU}$ for the $\mathrm{OH}$ temperature, $4.1 \pm 0.7 \mathrm{~K} / 100 \mathrm{SFU}$ for the $\mathrm{O}_{2}$ temperature and $2.0 \pm 0.5 \mathrm{~K} / 100 \mathrm{SFU}$ for the O1S temperature. The $\mathrm{F} 10.7$ trend in the $\mathrm{O}_{2}$ temperature is very close to the values in the aforementioned studies, and the trend in the $\mathrm{O} 1 \mathrm{~S}$ temperature is smaller. Our OH temperature shows a F10.7 trend that is much smaller in magnitude, compared to the studies in Table 2, and is negative. This might be due to the fact that the NRLMSISE-00 model that outputs the kinetic temperature does not explicitly include the F10.7 effect below $110 \mathrm{~km}$ in their model, and that there might be regions like in the $\mathrm{OH}$ airglow region that were under sampled. Our $\mathrm{OH}$ temperature also shows a weak negative Ap index trend $-0.1 \pm 0.02 \mathrm{~K} / \mathrm{nT}$ when compared to the trend in the $\mathrm{O}_{2}$ temperature $(\sim 0.6 \pm 0.03 \mathrm{~K} / \mathrm{nT})$ or O1S temperature $(\sim 0.4 \pm 0.03 \mathrm{~K} / \mathrm{nT})$. Since the Ap index effect is included explicitly above $90 \mathrm{~km}$ in the NRLMSISE-00 model, our results show that the airglow temperatures, especially the $\mathrm{O}_{2}$ and O1S temperatures, can respond rather significantly to geomagnetic activity.

To minimize the contamination of wave dynamics, we did not use the wave feature in the models, and the inputs to the models were the annual mean values, so that variations of dynamic nature on a shorter time scale would be averaged out. The airglow models (OHCD-and MACD) are sensitive to the inputs like the number densities and temperature from an atmospheric reference model. The simulation results can be different if these parameters show differences in the atmospheric reference models. Previous work by $[8,10]$ used the OHCD-90 and MACD-90, with the MSISE-90 as the atmospheric reference model, whereas this work used NRLMSISE-00 in the OHCD-00 and MACD-00 models. It would be interesting to see how big a difference there would be when we compare the results from these simulations. An update on [10] is planned in the near future. 
As is well known, the Earth's thermal structure is determined by the absorption of the incoming and re-radiated solar radiation. In the thermosphere from 80 to $600 \mathrm{~km}$, it is predominately heated by solar EUV radiation. The variations of EUV directly cause the thermosphere to vary on similar time scales and magnitudes. Since F10.7 is a proxy for solar EUV radiation, it is expected that the solar variability will directly affect the temperature in the region of interest.

Reference [23] used four decades of F10.7 and Ap index data to study the correlation between solar cycle variation and geomagnetic activity. Their study shows that F10.7 and the Ap index tracked each other well, but there were times when the Ap index lagged F10.7 from 1 to 4 years. That there is a correlation between F10.7 and the Ap index suggests that the influences of F10.7 and the Ap index on the atmosphere could be correlated as well. As such, we cannot do a linear regression of temperature with both F10.7 and the Ap index simultaneously, since it is inherently nonlinear and nonorthogonal. Instead, we found the F10.7 and Ap index trends separately, so that we could gain a better understanding of how the atmosphere would respond to these influences individually.

That F10.7 and the Ap index tracked each other is interesting and bears a closer look at how they are related to each other. As described in [24], a $10.7 \mathrm{~cm}$ solar radio flux measurement comprises a mix of a slowly varying component and the quiet sun background, and sometimes radio bursts. These components may each vary independently with time. The slowly varying component originates primarily in active regions of solar magnetic activity and has a broad spectral peak at about a $10 \mathrm{~cm}$ wavelength. So F10.7 values indicate the strength of solar magnetic activity, which in turns indicates the solar wind variability. On the other hand, the impact of solar wind variability on the atmosphere can appear through geomagnetic storms, magnetospheric substorms and changes of geomagnetic activity [25]. That the F10.7 values are closely related to the solar magnetic activity, and that solar wind variability can cause geomagnetic storms, which indicates that there should exist a close correlation between F10.7 and the Ap index, as supported by the study of [23]. Given that the F10.7 measurements comprise more than just the solar magnetic activity component, this might be the reason why solar cycle variation (F10.7) and geomagnetic activity (Ap index) are found to track each other well in some periods, but not always. Regarding how the temperature is affected by geomagnetic activity, it was suggested that the energy deposition from geomagnetic storm-related precipitating particles can lead to temperature variation in the MLT region [25].

The authors of [22] did a correlation analysis between MSIS-90 temperature and F10.7 variation at the $\mathrm{OH}$ airglow peak height at $87 \mathrm{~km}$, and they found that the MSIS- 90 model does not reproduce the solar cycle dependence of the observed $\mathrm{OH}$ airglow temperature at the South Pole Station. This is not surprising because "the F10.7 and Ap variations have not been carried below 110 and $90 \mathrm{~km}$, respectively, where their coefficient became insignificant" in the MSISE-90 model [17]. In this study, we used the NRLMSISE-00 model, and found that the simulated airglow temperatures in general do track F10.7 variation loosely and track the Ap index closely. We highly recommend that the F10.7 and Ap index variations be carried below the current altitudes in the NRLMSISE-00 model, to explicitly include their variations in the model output quantities.

Recent studies using meteor radar and Microwave Limb Sounder (MLS) on Aura satellite have shown that the mesospheric neutral density would change in response to geomagnetic storms [26,27]. The work of [10] also shows that atmospheric neutral density tracks geomagnetic storms closely. On the other hand, the MLS mesospheric temperature does not seem to show a clear response to geomagnetic storms [27], but our airglow temperatures do display a high correlation with geomagnetic activity. Yet another study using SABER zonal mean temperature in the lower thermosphere, in the altitude range of $100-120 \mathrm{~km}$, shows that it seemed to strongly correlate with the recurrent geomagnetic activity at periods of 9 days and 13.5 days, more so than with the solar EUV variability [28]. These conflicting results reveal that the actual mechanism of the Mesosphere Ionosphere Thermosphere (MIT) coupling during geomagnetic activity is still unknown. More work needs to be done in the area of observations and modeling, in order to better understand the mechanisms in the MIT coupling during geomagnetic activity. 


\section{Conclusions}

Airglow intensity-weighted temperature variations in response to the influences of $\mathrm{CO}_{2}$ gas concentration increase, solar cycle variation (F10.7 as a proxy) and geomagnetic activity (Ap index as a proxy) were simulated for a period of 60 years from 1960 to 2019. Two airglow chemistry dynamics models, OHCD-00 and MACD-00, were used in the simulations of $\mathrm{OH}(8,3)$ airglow, $\mathrm{O}_{2}(0,1)$ atmospheric band and $\mathrm{O}\left({ }^{1} \mathrm{~S}\right)$ greenline temperatures for three scenarios $\left(\mathrm{S} 1: \mathrm{CO}_{2}\right.$ gas concentration is fixed and $\mathrm{F} 10.7$ and the Ap index are allowed to change; S2: F10.7 and the Ap index are fixed and $\mathrm{CO}_{2}$ gas concentration is allowed to change; S3: F10.7, the Ap index, and $\mathrm{CO}_{2}$ gas concentration are allowed to change). Trends were deduced from the linear regression analysis of the simulated airglow temperatures.

Our S1 results show that the airglow temperatures are highly correlated with the Ap index and moderately correlated with F10.7. The $\mathrm{OH}$ temperature shows an anti-correlation with F10.7 and the Ap index. The trends are $\sim-1 \pm 0.24 \mathrm{~K} / 100 \mathrm{SFU}$ and $\sim-0.2 \pm 0.02 \mathrm{~K} / \mathrm{nT}$ in the $\mathrm{OH}$ temperature, $3.8 \pm 0.5 \mathrm{~K} / 100 \mathrm{SFU}$ and $\sim 0.51 \pm 0.02 \mathrm{~K} / \mathrm{nT}$ in the $\mathrm{O}_{2}$ temperature and $\sim 1.7 \pm 0.4 \mathrm{~K} / 100 \mathrm{SFU}$ and $\sim 0.3 \pm 0.01 \mathrm{~K} / \mathrm{nT}$ in the O1S temperature. Our S2 results show that all three airglow temperatures display a linear trend of $\sim-0.5 \mathrm{~K} /$ decade in response to the increase of $\mathrm{CO}_{2}$ gas concentration. Our S3 results show that the trends become $\sim-0.7 \pm 0.28 \mathrm{~K} / 100 \mathrm{SFU}$ and $\sim-0.1 \pm 0.002 \mathrm{~K} / \mathrm{nT}$ in the $\mathrm{OH}$ temperature, $4.1 \pm 0.7 \mathrm{~K} / 100 \mathrm{SFU}$ and $\sim 0.6 \pm 0.03 \mathrm{~K} / \mathrm{nT}$ in the $\mathrm{O}_{2}$ temperature, and $\sim 2.0 \pm 0.6 \mathrm{~K} / 100 \mathrm{SFU}$ and $\sim 0.4 \pm 0.03 \mathrm{~K} / \mathrm{nT}$ in the $\mathrm{O} 1 \mathrm{~S}$ temperature. This indicates that the increase of $\mathrm{CO}_{2}$ gas concentration tends to amplify airglow temperature variation, yielding larger F10.7 and Ap index trends in the $\mathrm{O}_{2}$ and $\mathrm{O} 1 \mathrm{~S}$ temperatures, and smaller trends in the $\mathrm{OH}$ temperature. The $\mathrm{O}_{2}$ temperature shows that it has the largest response to the influences of $\mathrm{F} 10.7$, the Ap index variations, and $\mathrm{CO}_{2}$ increase.

Our simulation results show that the airglow temperatures would decrease linearly in response to the increase of anthropogenic gas emissions. Further, geomagnetic activity can affect airglow temperatures and kinetic temperature rather significantly, in addition to what is already known about how the solar cycle variations can affect the atmospheric temperature. More work needs to be done in the area of observations, modeling and data analysis to learn more about the effects on the atmosphere caused by the increase of anthropogenic gas emission, solar cycle variation and geomagnetic activity.

Author Contributions: Conceptualization, T.-Y.H.; Formal analysis, T.-Y.H. and M.V.; Funding acquisition, T.-Y.H.; Investigation, T.-Y.H. and M.V.; Methodology, T.-Y.H.; Project administration, T.-Y.H.; Resources, T.-Y.H.; Software, M.V.; Writing—original draft, T.-Y.H. All authors have read and agreed to the published version of the manuscript.

Funding: This research was funded by US NSF AGS-1903346 to The Pennsylvania State University.

Acknowledgments: T.-Y. Huang and M. Vanyo acknowledge support from the US NSF AGS-1903346 to The Pennsylvania State University. $\mathrm{CO}_{2}$ gas concentration can be obtained from the NOAA website (http://www.esrl. noaa.gov/gmd/ccgg/trends/), F10.7 from the NASA website (http://omniweb.gsfc.nasa.gov/form/dx1.html), and the Ap index (nT) from the World Data Center for Geomagnetism, Kyoto website (http://wdc.kugi.kyoto-u.ac.jp/kp/).

Conflicts of Interest: The authors declare no conflict of interest. The funders had no role in the design of the study; in the collection, analyses, or interpretation of data; in the writing of the manuscript, or in the decision to publish results.

\section{References}

1. Roble, R.G.; Dickinson, E.E. How will changes in carbon dioxide and methane modify the mean structure of the mesosphere and thermosphere? Geophys. Res. Lett. 1989, 16, 1441-1444. [CrossRef]

2. Keating, G.M.; Tolson, R.H.; Bradford, M.S. Evidence of Long Term Global Decline in the Earth's Thermospheric Densities Apparently Related to Anthropogenic Effects. Geophys. Res. Lett. 2000, 27, 1523-1526. [CrossRef]

3. Emmert, J.T.; Picone, J.M.; Lean, J.L.; Knowles, S.H. Global Change in the Thermosphere: Compelling Evidence of a Secular Decrease in Density. J. Geophys. Res. 2004, 109, A02301. [CrossRef]

4. Emmert, J.T.; Picone, J.M.; Meier, R.R. Thermospheric Global Average Density Trends, 1967-2007, Derived from Orbits of 5000 Near-Earth Objects. Geophys. Res. Lett. 2008, 35, L05101. [CrossRef] 
5. Marcos, F.A.; Wise, J.O.; Kendra, M.J.; Grossbard, N.J.; Bowman, B.R. Detection of a Long-term Decrease in Thermospgeric Neutral Density. Geophys. Res. Lett. 2005, 32, L04103. [CrossRef]

6. Huang, T.-Y.; Kane, T.J. Examining Methods Used in Extracting Long-term Thermospheric Density Trends. J. Atmos. Solar-Terr. Phys. 2013, 97, 115. [CrossRef]

7. Shepherd, G.G.; Siddiqi, N.J.; Wiens, R.H.; Zhang, S. Airglow measurements of possible changes in the ionosphere and middle atmosphere. Adv. Space. Res. 1997, 20, 2127-2135. [CrossRef]

8. Huang, T.-Y. Simulations of Airglow Variations Induced by the $\mathrm{CO}_{2}$ Increase and Solar Cycle Variation From 1980 to 1991. J. Atmos. Solar-Terr. Phys. 2016, 147, 138-147. [CrossRef]

9. Huang, T.-Y. Global Warming's Effect on Mesospheric Airglow Emissions. In New Developments in Global Warming Research; Nova Science Publishers, Inc.: New York, NY, USA, 2013; pp. 103-116.

10. Huang, T.-Y. Influences of $\mathrm{CO}_{2}$ Increase, Solar Cycle Variation, and Geomagnetic Activity on Airglow From 1960 to 2015. J. Atmos. Solar-Terr. Phys. 2018, 171, 164-175. [CrossRef]

11. Picone, J.M.; Hedin, A.E.; Drob, D.P.; Aikin, A.C. NRLMSISE-00 empirical model of the atmosphere: Statistical comparisons and scientific issues. J. Geophys. Res. 2002, 107, 1468. [CrossRef]

12. Amaro-Rivera, Y.; Huang, T.-Y.; Urbina, J. On the Importance of an Atmospheric Reference Model: A Case Study on Gravity-Airglow Interactions. J. Atmos. Solar-Terr. Phys. 2018, 171, 260-268. [CrossRef]

13. Huang, T.-Y.; Hickey, M.P. On the latitudinal variations of the non-periodic response of minor species induced by a dissipative gravity-wave packet in the MLT region. J. Atmos. Solar-Terr. Phys. 2007, 69, 741-757. [CrossRef]

14. Huang, T.-Y.; Hickey, M.P. Secular variations of OH nightglow emission and of the $\mathrm{OH}$ intensity-weighted temperature induced by gravity-wave forcing in the MLT region. Adv. Space Res. 2008, 41, 1478-1487. [CrossRef]

15. Huang, T.-Y.; George, R. Simulations of Gravity Wave-induced Variations of the $\mathrm{OH}(8,3), \mathrm{O}_{2}(0,1)$, and $\mathrm{O}\left({ }^{1} \mathrm{~S}\right)$ Airglow Emissions in the MLT Region. J. Geophys. Res. Space Phys. 2014, 119, 2149-2159. [CrossRef]

16. Huang, T.-Y. Gravity Waves-induced Airglow Temperature Variations, Phase Relationships, and Krassovsky Ratio for $\mathrm{OH}(8,3)$ Airglow, $\mathrm{O}_{2}(0,1)$ Atmospheric Band, and $\mathrm{O}\left({ }^{1} \mathrm{~S}\right)$ Greenline in the MLT Region. J. Atmos. Solar-Terr. Phys. 2015, 130-131, 68-74. [CrossRef]

17. Hedin, A.E. Extension of the MSIS thermosphere model into the middle and lower thermosphere. J. Geophys. Res. 1991, 96, 1159-1172. [CrossRef]

18. Kalicinsky, C.; Knieling, P.; Koppmann, R.; Offermann, D.; Steinbrecht, W.; Wintel, J. Long-term Dynamics of $\mathrm{OH}^{*}$ Temperatures Over Central Europe: Trends and Solar Correlations. Atmos. Chem. Phys. 2016, 16, 15033-15047. [CrossRef]

19. Perminov, V.I.; Semenov, A.I.; Medvedva, I.V.; Zheleznov, Y.A. Variability of Mesopause Temperature from Hydroxyl Airglow Observations over Mid-Latitudinal Sites, Zvenigorod and Troy, Russia. Adv. Space Res. 2014, 54, 2511-2517. [CrossRef]

20. Holmen, S.E.; Dyrland, M.E.; Sigernes, F. Long-term Trends and the Effect of Solar Cycle Variations on Mesospheric Winter Temperatures Over Longyearbyen, Svalbard (78 N). J. Geophys. Res. Atmos. 2014, 119, 6596-6608. [CrossRef]

21. Hall, C.M.; Dyrland, M.E.; Tsutsumi, M.; Mulligan, F.J. Temperature Trends at 90 km Over Svalbard, Norway (78 N 16 ${ }^{\circ}$ E), Seen in one Decade of Meteor Radar Observations. J. Geophys. Res. 2012, 117, D08104. [CrossRef]

22. Azeem, S.M.I.; Sivjee, G.G.; Won, Y.-I.; Mutiso, C. Solar Cycle Signature and Secular Long-term Trend in OH Airglow Temperature Observations at South Pole, Antarctica. J. Geophys. Res. 2007, 112, A01305. [CrossRef]

23. Verbanac, G.; Vrsnak, B.; Temmer, M.; Mandea, M.; Korte, M. Four decades of geomagnetic and solar activity: 1960-2001. J. Atmos. Solar-Terr. Phys. 2010, 72, 607-616. [CrossRef]

24. Tapping, K.F. The $10.7 \mathrm{~cm}$ solar radio flux (F10.7). Space Weather 2013, 11, 394-406. [CrossRef]

25. Laštovička, J. Effects of geomagnetic storms in the lower ionosphere, middle atmosphere and troposphere. J. Atmos. Solar-Terr. Phys. 1996, 58, 831-843. [CrossRef]

26. Yi, W.; Reid, I.M.; Xue, X.; Younger, J.P.; Murphy, D.J.; Chen, T.; Dou, X. Response of Neutral Mesospheric Density to Geomagnetic Forcing. Geophys. Res. Lett. 2017, 44, 8647-8655. [CrossRef]

27. Yi, W.; Reid, I.M.; Xue, X.; Murphy, D.J.; Hall, C.M.; Tsutsumi, M.; Ning, B.; Li, G.; Younger, J.P.; Chen, T.; et al. High- and Middle-Latitude Neutral Mesospheric Density Response to Geomagnetic Storms. Geophys. Res. Lett. 2018, 45, 436-444. [CrossRef] 
28. Jiang, G.; Wang, W.; Xu, J.; Yue, J.; Burns, A.G.; Lei, J.; Mlynczak, M.G.; Rusell, J.M. Responses of the Lower Thermospheric Temperature to the 9 Day and 13.5 Day Oscillations of Recurrent Geomagnetic Activity. J. Geophys. Res. Space Physics 2014, 119, 4841-4859. [CrossRef]

C 2020 by the authors. Licensee MDPI, Basel, Switzerland. This article is an open access article distributed under the terms and conditions of the Creative Commons Attribution (CC BY) license (http://creativecommons.org/licenses/by/4.0/). 